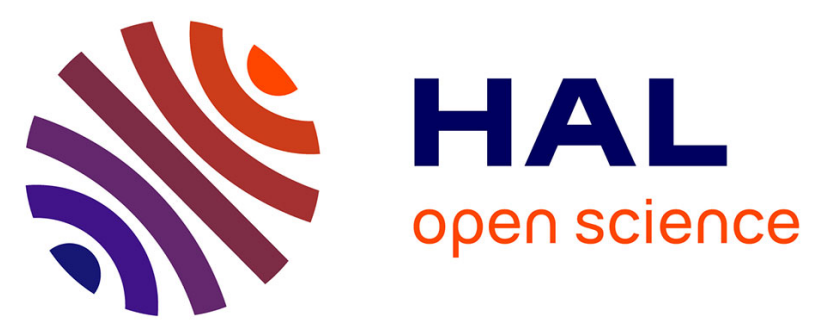

\title{
Unique Class of Enantiopure N-Heterocyclic Carbene Half-Sandwich Iridium(III) Complexes with Stable Configurations: Probing Five-Membered versus Six-Membered Iridacycles
}

Antoine Groué, Jean-Philippe Tranchier, Marie-Noelle Rager, Geoffrey Gontard, Marion Jean, Nicolas Vanthuyne, Harrison R. Pearce, Andrew L. Cooksy, Hani Amouri

\section{- To cite this version:}

Antoine Groué, Jean-Philippe Tranchier, Marie-Noelle Rager, Geoffrey Gontard, Marion Jean, et al.. Unique Class of Enantiopure N-Heterocyclic Carbene Half-Sandwich Iridium(III) Complexes with Stable Configurations: Probing Five-Membered versus Six-Membered Iridacycles. Inorganic Chemistry, 2019, 58 (5), pp.2930-2933. 10.1021/acs.inorgchem.8b03469 . hal-02166440

\section{HAL Id: hal-02166440 \\ https://hal.sorbonne-universite.fr/hal-02166440}

Submitted on 31 Oct 2019

HAL is a multi-disciplinary open access archive for the deposit and dissemination of scientific research documents, whether they are published or not. The documents may come from teaching and research institutions in France or abroad, or from public or private research centers.
L'archive ouverte pluridisciplinaire HAL, est destinée au dépôt et à la diffusion de documents scientifiques de niveau recherche, publiés ou non, émanant des établissements d'enseignement et de recherche français ou étrangers, des laboratoires publics ou privés. 


\title{
Unique Class of Enantiopure $N$-Heterocyclic Carbene Half- Sandwich Ir(III) Complexes With Stable Configurations: Probing Five-membered Versus Six-membered Iridacycles.
}

\author{
Antoine Groué, ${ }^{\mathrm{a}}$ Jean-Philippe Tranchier, ${ }^{\mathrm{a}}$ Marie-Noelle Rager, ${ }^{\mathrm{b}}$ Geoffrey Gontard, ${ }^{\mathrm{a}}$ Marion Jean, ${ }^{\mathrm{c}}$ \\ Nicolas Vanthuyne, ${ }^{\mathrm{c}}$ Harrison R. Pearce, ${ }^{\mathrm{d}}$ Andrew L. Cooksy, ${ }^{\mathrm{d}}$ and Hani Amouri, ${ }^{* a}$ \\ aSorbonne Université- Campus Pierre et Marie Curie, Institut Parisien de Chimie Moléculaire (IPCM) UMR GNRS \\ 8232, 4 place Jussieu, 75252 Paris cedex 05, France. ${ }^{\mathrm{b} C h i m i e}$ ParisTech, PSL University, NMR Facility, F-75005 Paris, \\ France. 'Aix Marseille Univ, GNRS, Centrale Marseille, iSm2, Marseille, France. ${ }^{d}$ Department of Chemistry and Bio- \\ chemistry, 5500 Campanile Drive, San Diego State University, San Diego, California 92182-1030. USA
}

\section{Supporting Information Placeholder}

\begin{abstract}
A unique class of enantiopure $\mathcal{N}$ heterocylic carbene half-sandwich iridium complexes is reported. These compounds display stable configurations at the metal center as demonstrated by their chiroptical properties. Remarkably, due to the nature of the naphthalimide molecule, two isomers containing fivemembered $(R)$ - 2a,,$(S)$-2a and six-membered $(R)$-2b, $(S)$ 2b iridacycles were obtained. DFT-calculations are advanced to rationalize their relative stability.
\end{abstract}

Half-sandwich compounds with three-legged piano stool geometry with different substituents are archetypal examples of optically active chirality-at-metal center. ${ }^{1-3}$ Pioneering work of Brunner et al. and Gladysz et al. on the preparation of optically active $\left[\mathrm{CpMn}(\mathrm{CO})(\mathrm{NO})\left(\mathrm{PPh}_{3}\right)\right]\left[\mathrm{PF}_{6}\right] \quad$ and $\left[\mathrm{CpRe}(\mathrm{L})(\mathrm{NO})\left(\mathrm{PPh}_{3}\right)\right]\left[\mathrm{BF}_{4}\right]\left(\mathrm{L}=\mathrm{CH}_{2} \mathrm{Cl}_{2}, \mathrm{C}_{6} \mathrm{H}_{5} \mathrm{Cl}\right)$ complexes gave an impetus to the development of modern chiral organometallic chemistry. ${ }^{4,5}$ Depending on the metal and the nature of ligands as well, such compounds tend to exhibit labile or stable configuration in solution. For instance, the related chiral Cp*Ir complexes were found to exhibit labile configuration in solution. ${ }^{6-8}$ More recently, however, the use of strongly coordinating $\mathcal{N}$ heterocyclic carbene (NHC) ligands brought some stability to the metal center but only a few examples of enantiopure half-sandwich Cp*Ir complexes were reported by Crassous and Peris. ${ }^{9,}, 10$

On the other hand half-sandwich metal complexes have received considerable attention due to their importance in medicinal chemistry ${ }^{11,12}$, materials science ${ }^{13}$, 14 and catalysis. ${ }^{15-17}$ Thus we sought to design a novel class of stable half-sandwich Cp*Ir complexes in which the NHC unit is directly attached to a naphthalimide molecule (NI). The latter adopts a planar structure and contains three fused arenes, which should bring strong configurational rigidity around the metal center. Moreover it might also provide an entry to a novel class of luminescent compounds. To demonstrate the viability of our strategy, we first prepared the naphthalimideimidazolium salt $(\mathbf{1})$ according to our described synthetic procedure. ${ }^{18-20}$ Significantly, treatment of two equivalents of 1 with $[\mathrm{Cp} * \operatorname{Ir}(\mu-\mathrm{Cl}) \mathrm{Cl}]_{2}$ in the presence of $\mathrm{Ag}_{2} \mathrm{O}$ and
$\mathrm{NBu}_{4} \mathrm{I}$ in $\mathrm{CH}_{3} \mathrm{CN}$ for overnight reflux afforded in onepot reaction the iridium carbene complexes [Cp*Ir(NI$\mathrm{NHC}) \mathbf{I}$ (2a and $\mathbf{2} \mathbf{b})$ in 1:1 ratio. The regioisomers $\mathbf{2 a}$ and $\mathbf{2 b}$ were separated by column chromatography and fully characterized. They differ only by the size of the iridacycle, whether five-membered or six-membered, constructed by the carbene and the naphthalimide units (Figure 1). Indeed due to the structure of the naphthalimide molecule, which contains two fused arenes available for metal coordination, the iridacyclization process occurs in two different ways. This phenomenon has not been observed before in the literature for this class of half-sandwich metal carbene complexes.

The ${ }^{1} \mathrm{H}-\mathrm{NMR}$ of $\mathbf{2} \mathbf{a}$ recorded in $\mathrm{CDCl}_{3}$ presented six multiplets in the range of $\delta 7.1 \mathrm{ppm}$ and $\delta 9.2 \mathrm{ppm}$ corresponding to the aromatic protons of the naphthalimide unit and to the diene protons of the NHC moiety. The $n^{-}$ $\mathrm{Bu}$ group of the naphthalimide unit displayed four multiplets in the range $\delta 0.9 \mathrm{ppm}$ to $\delta 4.3 \mathrm{ppm}$ while the methyl group of the carbene unit appeared as a singlet at $\delta 3.98 \mathrm{ppm}$. The Cp*Ir moiety gave a singlet at $\delta 1.96$ ppm. The ${ }^{1} \mathrm{H}-\mathrm{NMR}$ of isomer $\mathbf{2} \mathbf{b}$ in $\mathrm{CDCl}_{3}$ displayed a marked difference with respect to $\mathbf{2 a}$ where the Cp*Ir protons appeared downfield at $\delta 1.54 \mathrm{ppm}$ and the aromatic protons of the naphthalimide and NHC moiety appeared in the range of $\delta 7.1$ to $\delta 8.6 \mathrm{ppm}$ and displayed a different pattern. Moreover 2D COSY, ROESY, HSQG and HMBC experiments allowed us to fully characterize both isomers (See supporting information Figures S1-S7). In addition, the molecular structures of isomers $r a c-\mathbf{2} \mathbf{a}$ and $r a c-\mathbf{2 b}$ were also ascertained by X-ray crystallography.

Crystals of cyclometalated carbene complex 2a were obtained from a mixture $\mathrm{CH}_{2} \mathrm{Cl}_{2} / \mathrm{Et}_{2} \mathrm{O}$ by slow diffusion. A view of the molecule is given in Figure 2. The structure of $\mathbf{2} \mathbf{a}$ is in accord with the spectroscopic data and confirms the formation of a five-membered iridacycle. As expected, the metal adopts a distorted tetrahedral geometry. The structure packing in the crystal shows the formation of a dimer assembly between two adjacent molecules, which are arranged in a head-to-tail fashion where each complex adopts an opposite configuration at the 
metal center $\left(S_{\mathrm{Ir}}, R_{\mathrm{Ir}}\right)$. The dimer assembly arises from weak non-covalent $\mathrm{C}-\mathrm{H}---\pi$ interactions $(\mathrm{CH}---\mathrm{C}=$ 3.60(3) $\AA$ ) between the $n$-Bu group and the naphthalimide moiety (Figure S8). ${ }^{21}$
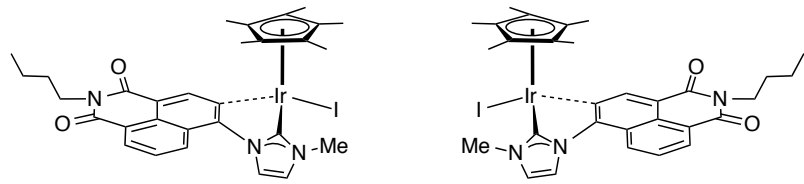

(S)-[Cp* $\operatorname{Ir}(\mathrm{NI}-\mathrm{NHC})]$ (S)-(2a)

$$
(R)-\left[\mathrm{Cp}^{*} \mathrm{Ir}(\mathrm{NI}-\mathrm{NHC}) \mathrm{I}\right](R)-(\mathbf{2 a})
$$
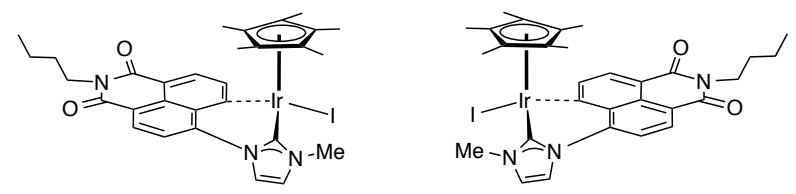

$(S)-\left[\mathrm{Cp}{ }^{*} \mathrm{Ir}(\mathrm{NI}-\mathrm{NHC})\right](S)-(\mathbf{2 b})$

$\left.(R)-\left[\mathrm{Cp} \mathrm{I}^{*} \mathrm{I}(\mathrm{NI}-\mathrm{NHC})\right]\right](R)-(\mathbf{2 b})$

Figure 1. Schematic drawings of enantiopure carbene regioisomeric complexes (S)-2a, $(\mathrm{R})-\mathbf{2} \mathbf{a}$, and $(\mathrm{S})-\mathbf{2} \mathbf{b},(\mathrm{R})-$ 2b described in this work. Priority sequence of ligands: I $>\eta^{5}-\mathrm{C}_{5}>\mathrm{C}$-carbene $>$ C-arene. ${ }^{22,23}$

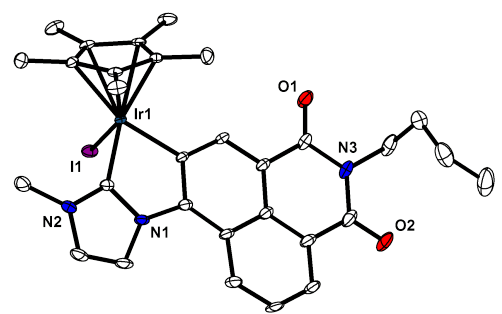

Figure 2. Molecular structure of complex rac-2a.

In a similar fashion, crystals of [Cp* $\operatorname{Ir}(\mathrm{NI}-\mathrm{NHC}) \mathbf{I}(\mathbf{2} \mathbf{b})$ were obtained by slow diffusion of diethylether into a saturated $\mathrm{CH}_{2} \mathrm{Cl}_{2}$ solution of the complex. Details regarding crystal structure determination are given in the ESI. A view of $\mathbf{2 b}$ is shown in Figure 3. The structure of complex 2b confirms the formation of the target molecule and shows that the iridacycle is composed of a six membered ring. The configuration around the iridium center is a distorted tetrahedral geometry. The crystal structure adheres to a similar head-to-tail dimer assembly as rac-2a, but with C-H--- $\pi$ interaction $(\mathrm{C} 28 \mathrm{~A}---\mathrm{C} 17=$ 3.41(3) $\AA$ ) between the n-Bu group and the Cp*Ir moiety (Figure S9).21

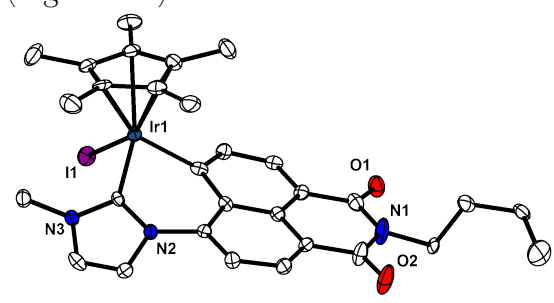

Figure 3. Molecular structure of complex $r a c-\mathbf{2 b}$.

To examine their configurational stability we decided to resolve these compounds into their single enantiomers and to investigative their chiroptical properties in solution (vide infra).

Enantiopure [Cp*Ir(NI-NHC)I] complexes $(S)$ 2a, $(R)-2 a$, and $(S)-2 b,(R)-2 b$
The optically active compounds $(\boldsymbol{S})-\mathbf{2} \mathbf{a},(\boldsymbol{R}) \mathbf{- 2} \mathbf{a}$, and $(\boldsymbol{S})-\mathbf{2 b},(\boldsymbol{R}) \mathbf{- 2 b}$ were obtained by resolving the racemic samples using chiral column chromatography techniques. Full experimental details are given in the supporting information. Gratifyingly all of our enantiopure compounds were found to display stable configuration in strongly coordinated $\mathrm{CH}_{3} \mathrm{CN}$ solution and did not epimerize upon standing for several days in solution as demonstrated by their CD curves (vide infra). The same behavior is observed in $\mathrm{CH}_{2} \mathrm{Cl}_{2}$ (Figures $\mathrm{S} 15-\mathrm{S} 16$ ).

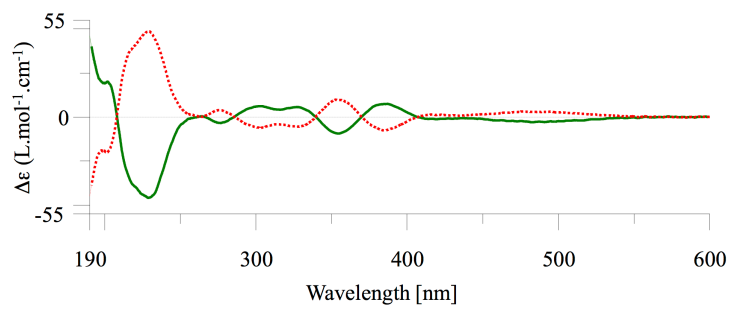

Figure 4. CD traces of $\boldsymbol{S}-\mathbf{2 a}$ and $\boldsymbol{R}$-2a showing perfect mirror image. Recorded in $\mathrm{CH}_{3} \mathrm{CN}$ at $\mathrm{C}=0.24 \mathrm{mM}$

The $\mathrm{CD}$ traces recorded in $\mathrm{CH}_{3} \mathrm{CN}$ show an excellent mirror-image relationship for the two enantiomers of 2a (Figure 4). In both cases, several peaks (with opposite signs for the two enantiomers) are visible at 240, 260, 290 and $320 \mathrm{~nm}$, associated with the polarized $\pi-\pi^{*}$ transition of the naphthalimide unit. Moreover, bands of weak intensity attributed principally to MLCT electronic transitions are also visible at 350, 390 and $480 \mathrm{~nm}$.

We then investigated the chiroptical properties of the other isomer $\mathbf{2 b}$ to see whether the presence of a six membered cycle might affect the Cotton transitions (Figure 5).

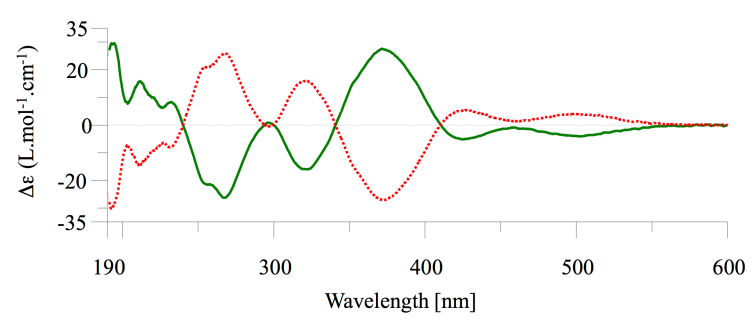

Figure 5. GD traces of $\boldsymbol{S}-\mathbf{2} \mathbf{b}$ and $\boldsymbol{R}$-2 b showing perfect mirror image. Recorded in $\mathrm{CH}_{3} \mathrm{CN}$ at $\mathrm{C}=0.24 \mathrm{mM}$.

Again the $\mathrm{CD}$ curves recorded in $\mathrm{CH}_{3} \mathrm{CN}$ show an excellent mirror-image relationship for the two enantiomers of 2b. We also notice that several peaks (with opposite signs for the two enantiomers) are visible at 240, 260, 290 and $320 \mathrm{~nm}$, associated with the polarized $\pi-\pi^{*}$ transition of the naphthalimide unit. Moreover, bands of more pronounced intensity relative to $\mathbf{2 a}$ attributed to MLCT electronic transitions are also visible at 370,420 and 520 $\mathrm{nm}$. These bands extend more into the visible red region compared to the five membered isomer $2 \mathbf{a}$. We then attempted to obtain crystals of the enantiopure compounds in order to compare it to the racemic analogues. After many attempts, gratifyingly we were able to obtain convenient crystals of isomer $(R)$-2b for an X-ray determination (vide infra). 


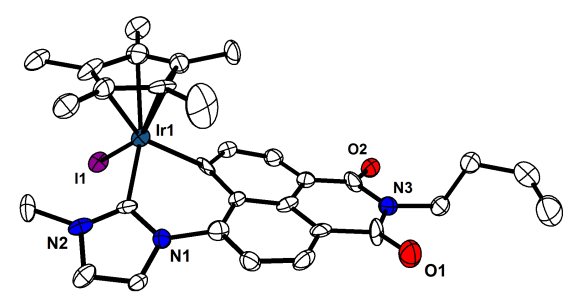

Figure 6. Molecular structure of complex $(R)-\mathbf{2 b}$.

Complex $(R)$-2b crystallizes in the Sohncke space group $P 2{ }_{1}$. A view of the complex is shown in Figure 6 . The absolute structure was determined by refinement of the Flack x parameter equal to 0.033(10).24-26 The structure confirmed the formation of the sixmembered cycloiridated carbene isomer with $(R)$ configuration. The iridium center adopts a pseudotetrahedral geometry and is bound symmetrically to : $\eta$ Cp*, the NI carbon centers, NHC unit and to the iodide halogen. The Ir---carbene bond distance is 2.03(2) $\AA$ similar to $1.97(1) \AA$ reported for the analogous racemic compound. The solid-state packing, on the other hand, shows a completely different arrangement from that observed for the racemic complex $\mathbf{2 b}$. Indeed in the enantiopure complex $(R)$-2b the individual molecules adopt the same configuration and form $1 \mathrm{D}$ supramolecular assemblies though non-covalent C-H--- $\pi$ interactions $(\mathrm{C} 17--\mathrm{C} 22)=3.42(5) \AA)$ between the NI unit and the Cp*Ir moiety (Figure S10). ${ }^{21}$

We then investigated the solution behavior of both regioisomers in order to see whether a conversion of one regioisomer to the other might occur. Thus, refluxing isomer $2 \mathbf{a}$ in $\mathrm{CD}_{3} \mathrm{CN}$ for $24 \mathrm{~h}$ resulted in no alteration and the starting material remained unchanged. Moreover when isomer $\mathbf{2 b}$ was heated under similar conditions no formation of $\mathbf{2 a}$ was observed. These results suggest that both compounds are stable in solution even at high temperature. This stability arises from the nature of the NIcarbene ligand that acts as a clamp and strongly chelates the metal center.

To shed light on their relative stability and mechanism of their formation, relative energies and other properties both complexes were calculated by density functional theory (DFT). The free energies of $\mathbf{2 a}$ and $\mathbf{2 b}$ were found to be remarkably similar, differing by less than $2.2 \mathrm{kcal} / \mathrm{mol}$ in all our calculations, employing different combinations of DFT method, basis set, and solvation model. Indeed, at the highest quality calculations employed Truhlar's M0627 DFT method and a mixed pc-2/cc-pVDZ-pp basis ${ }^{28,} 29 "$, the two compounds were found to have equal free energies within 0.1 $\mathrm{kcal} / \mathrm{mol}$. These differences are well within the expected error of these calculations, a result that is consistent with the observation of both species in solution. There appears to be a balance of destabilizing ring strains in the two isomers, with the $\mathbf{2 a}$ iradacycle suffering from small bond angles $\left(\mathrm{C}-\mathrm{Ir}-\mathrm{C}=76^{\circ}\right.$, compared to $86^{\circ}$ in $\mathbf{2} \mathbf{b}$; $\mathrm{sp}^{2}$ bond angles $=111.5^{\circ}$ and $\left.114.5^{\circ}\right)$ whereas the conjugation of the arene system in $\mathbf{2} \mathbf{b}$ is disrupted by a $25^{\circ}$ twist of the imidazole unit relative to the neighboring naphthyl ring (compared to an $8^{\circ}$ twist in 2a). Surprisingly, alt- hough $2 \mathbf{a}$ has the more constrained ring system, frequency corrections consistently improve the relative stability of $\mathbf{2} \mathbf{a}$ by about $0.5 \mathrm{kcal} / \mathrm{mol}$. This primarily results from small shifts to higher arene stretching frequencies in $\mathbf{2 b}$, because the partial loss of naphthyl-imidazolyl conjugation strengthens the force constants within each ring. The calculations have been carried out only on the monomers, so we are not able to directly compare lattice energies. However, we note that the same 1-D chain assembly observed for $\mathbf{2} \mathbf{b}$ is not available to $\mathbf{2} \mathbf{a}$, because the $n$-Bu axis is perpendicular to the Ir-Cp axis in $\mathbf{2 a}$. Computed CD and UV/vis spectra are also found to be consistent with experiment (ESI Figures S17-S18).

The supporting information includes details of the computational methods, including predicted UV spectra and a brief MO analysis of the principal electronic transitions.

\section{CONCLUSION}

In this paper we reported a unique class of enantiopure $\mathrm{N}$-heterocylic carbene complexes displaying five- and sixmembered iridacycles not reported before. Remarkably these regioisomeric compounds display stable configuration in solution thanks to the naphthalimide-C-NHCchelate as demonstrated by their chiroptical properties. The use and future applications of these compounds are currently under investigation.

\section{ASSOCIATED CONTENT}

The Supporting Information is available free of charge on the ACS Publications website. The synthesis and separation of complexes $S-\mathbf{2} \mathbf{a}, R-\mathbf{2} \mathbf{a}$ and $S$ 2b, $R$-2b. ${ }^{1} \mathrm{H},{ }^{13} \mathrm{C}$ and $2 \mathrm{D}$ ROESY Spectra of complexes 2a and 2b (Figures S1-S7). X-ray molecular structures (Figures S8-S10) UV and ECD spectra are given (Figures S11-S16). DFT calculations (Figures S17-S18). CCDG reference numbers 18801131880115 contain crystallographic data for complexes $r a c-2 a, r a c-2 b$ and $R-\mathbf{2 b}$ presented in this paper. These data can be obtained free of charge from the Cambridge Crystallographic Data Gentre via www.ccdc.cam.ac.uk/data_request/cif.

\section{AUTHOR INFORMATION}

\section{Corresponding Author}

*E-mail: hani.amouri@sorbonne-universite.fr. Phone: +33-1-44273083.

\section{Author Contributions}

The manuscript was written through contributions of all authors. All authors have given approval to the final version of the manuscript.

\section{ACKNOWLEDGMENT}

Sorbonne Université-Campus Pierre et Marie Curie, CNRS are gratefully acknowledged, and Ile de France Region for financial support of $500 \mathrm{MHz}$ NMR spectrometer of Chimie-Paristech in the framework of the SESAME equipment project. 


\section{REFERENCES}

1. von Zelewsky, A. Stereochemistry of Coordination Compounds. Wiley: Chichester, U.K., 1996; p 254 pp.

2. Collet, A.; Crassous, J.; Dutasta, J. P.; Guy, L. Molécules Chirales: Stéreochime et Propriétes. EDP Sciences: 2006.

3. Amouri, H.; Gruselle, M. Chirality in Transition Metal Chemistry:Molecules, Supramolecular Assemblies and Materials. Wiley: Chichester, U.K., 2008.

4. Brunner, H. Optical Activity at an Asymmetrical Manganese Atom. Angew. Chem. Int. Ed. 1969, 8, 382-383.

5. Merrifield, J. H.; Strouse, C. E.; Gladysz, J. A. Synthesis, Optical Resolution, and Absolute-Configuration of Pseudotetrahedral Organorhenium Complexes ( $\eta$ $\left.\mathrm{C}_{5} \mathrm{H}_{5}\right) \mathrm{Re}(\mathrm{NO})\left(\mathrm{PPh}_{3}\right)(\mathrm{X})$. Organometallics 1982, 1, 1204-1211.

6. Brunner, H. Stability of the metal configuration in chiral-at-metal half-sandwich compounds. Eur. f. Inorg. Chem. 2001, 905-912.

7. Mimassi, L.; Guyard-Duhayon, C.; Rager, M. N.; Amouri, H. Chiral recognition and resolution of the enantiomers of supramolecular triangular hosts: Synthesis, circular dichroism, NMR, and X-ray molecular structure of $[\mathrm{Li}$ $\left.\subset(\mathrm{R}, \mathrm{R}, \mathrm{R})-\{\mathrm{Cp} * \mathrm{Rh}(5 \text {-chloro-2,3-dioxopyridine })\}_{3}\right][\Delta$ TRISPHAT]. Inorg. Chem. 2004, 43, 6644-6649.

8. Mimassi, L.; Cordier, C.; Guyard-Duhayon, C.; Mann, B. E.; Amouri, H. Chiral supramolecular triangular hosts: Anion metathesis, solution behavior, and high stability of the metal configuration. Organometallics 2007, 26, 860-864.

9. Hellou, N.; Jahier-Diallo, C.; Basle, O.; SrebroHooper, M.; Toupet, L.; Roisnel, T.; Caytan, E.; Roussel, C.; Vanthuyne, N.; Autschbach, J.; Mauduit, M.; Crassous, J. Electronic and chiroptical properties of chiral cycloiridiated complexes bearing helicenic NHC ligands. Chem. Commun. 2016, 52, 9243-9246.

10. Corberan, R.; Sanau, M.; Peris, E. Highly stable Cp*-Ir(III) complexes with N-heterocyclic carbene ligands as C$\mathrm{H}$ activation catalysts for the deuteration of organic molecules. 7. Am. Chem. Soc. 2006, 128, 3974-3979.

11. Liu, Z.; Sadler, P. J. Organoiridium Complexes: Anticancer Agents and Catalysts. Acc. Chem. Res. 2014, 47, 1174-1185.

12. Liu, Z.; Habtemariam, A.; Pizarro, A. M.; Fletcher, S. A.; Kisova, A.; Vrana, O.; Salassa, L.; Bruijnincx, P. C. A.; Clarkson, G. J.; Brabec, V.; Sadler, P. J. Organometallic halfsandwich iridium anticancer complexes. 7. Med. Chem. 2011, 54, 3011-3026.

13. Grotjahn, D. B.; Brown, D. B.; Martin, J. K.; Marelius, D. C.; Abadjian, M.-C.; Tran, H. N.; Kalyuzhny, G.; Vecchio, K. S.; Specht, Z. G.; Cortes-Llamas, S. A.; MirandaSoto, V.; van Niekerk, C.; Moore, C. E.; Rheingold, A. L. Evolution of Iridium-Based Molecular Catalysts during Water Oxidation with Ceric Ammonium Nitrate. 7. Am. Chem. Soc. 2011, 133, 19024-19027.

14. Schulze, M.; Steffen, A.; Wurthner, F. Near-IR Phosphorescent Ruthenium(II) and Iridium(III) Perylene Bisimide Metal Complexes. Angew. Chem. Int. Ed. 2015, 54, 1570-1573.
15. Specht, Z. G.; Cortes-Llamas, S. A.; Tran, H. N.; van Niekerk, C. J.; Rancudo, K. T.; Golen, J. A.; Moore, C. E.; Rheingold, A. L.; Dwyer, T. J.; Grotjahn, D. B. Enabling Bifunctionality and Hemilability of N-Heteroaryl NHC Complexes. Chem. Eur. F. 2011, 17, 6606-6609.

16. Gomez-Lopez, J. L.; Chavez, D.; Parra-Hake, M.; Royappa, A. T.; Rheingold, A. L.; Grotjahn, D. B.; MirandaSoto, V. Synthesis and reactivity of bis(protic N-heterocyclic carbene)iridium(III) complexes. Organometallics 2016, 35, 31483153.

17. Peris, E. Smart N-Heterocyclic Carbene Ligands in Catalysis. Chem. Rev. 2018, 118, 9988-10031.

18. Lanoe, P. H.; Chan, J.; Gontard, G.; Monti, F.; Armaroli, N.; Barbieri, A.; Amouri, H. Deep-Red Phosphorescent Iridium(III) Complexes with Chromophoric NHeterocyclic Carbene Ligands: Design, Photophysical Properties, and DFT Calculations. Eur. 7. Inorg. Chem. 2016, 1631-1634.

19. Lanoe, P. H.; Najjari, B.; Hallez, F.; Gontard, G.; Amouri, H. N-Heterocyclic Carbene Coinage Metal Complexes Containing Naphthalimide Chromophore: Design, Structure, and Photophysical Properties. Inorganics 2017, 5.

20. Lanoe, P. H.; Chan, J.; Groue, A.; Gontard, G.; Jutand, A.; Rager, M. N.; Armaroli, N.; Monti, F.; Barbieri, A.; Amouri, H. Cyclometalated N-heterocyclic carbene iridium(III) complexes with naphthalimide chromophores: a novel class of phosphorescent heteroleptic compounds. Dalton Transactions 2018, 47, 3440-3451.

21. McCrea-Hendrick, M. L.; Bursch, M.; Gullett, K. L.; Maurer, L. R.; Fettinger, J. C.; Grimme, S.; Power, P. P. Counterintuitive Interligand Angles in the Diaryls $\mathrm{E}\left\{\mathrm{C}_{6} \mathrm{H}_{3}-2,6\right.$ $\left.\left(\mathrm{C}_{6} \mathrm{H}_{2}-2,4,6-\mathrm{i} \mathrm{Pr}_{3}\right)_{2}\right\}_{2}(\mathrm{E}=\mathrm{Ge}, \mathrm{Sn}$, or $\mathrm{Pb})$ and Related Species: The Role of London Dispersion Forces. Organometallics 2018, 37, 2075-2085.

22. Stanley, K.; Baird, M. C. F. Am. Chem. Soc. 1975, 97, 6598-6599.

23. Merrifield, J. H.; Fernandez, J. M.; Buhro, W. E.; Gladysz, J. A. Cleavage of the Rhenium Methyl Bond of ( $\boldsymbol{\eta}$ $\left.\mathrm{C}_{5} \mathrm{H}_{5}\right) \mathrm{Re}(\mathrm{NO})\left(\mathrm{PPh}_{3}\right)\left(\mathrm{CH}_{3}\right)$ by Protic and Halogen Electrophiles - Stereochemistry at Rhenium. Inorg. Chem. 1984, 23, 40224029 .

24. Flack, H. D.; Bernardinelli, G. Reporting and evaluating absolute-structure and absolute-configuration determinations. F. Appl. Crsytal. 2000, 33, 1143-1148.

25. Flack, H. D. Chiral and achiral crystal structures. Helv. Chim. Acta 2003, 86, 905-921.

26. Flack, H. D.; Bernardinelli, G. The use of X-ray crystallography to determine absolute configuration. Chirality 2008, 20, 681-690.

27. Zhao, Y.; Truhlar, D. G. The M06 suite of density functionals for main group thermochemistry, thermochemical kinetics, noncovalent interactions, excited states, and transition elements: two new functionals and systematic testing of four M06-class functionals and 12 other functionals. Theor. Chem. Acc. 2008, 120, 215-241.

28. Jensen, F. Polarization consistent basis sets: Principles. F. Chem. Phys. 2001, 115, 9113-9125.

29. Peterson, K. A.; Figgen, D.; Dolg, M.; Stoll, H. Energy-consistent relativistic pseudopotentials and correlation consistent basis sets for the $4 d$ elements Y-Pd. 7. Chem. Phys. 2007, 126 . 
SYNOPSIS: A unique class of enantiopure $\mathcal{N}$-heterocylic carbene half-sandwich iridium complexes obtained under two regioisomeric forms, not observed before, is described. These compounds display stable configuration at metal center and their molecular structures, chiroptical properties and DFT calculations are presented and discussed.

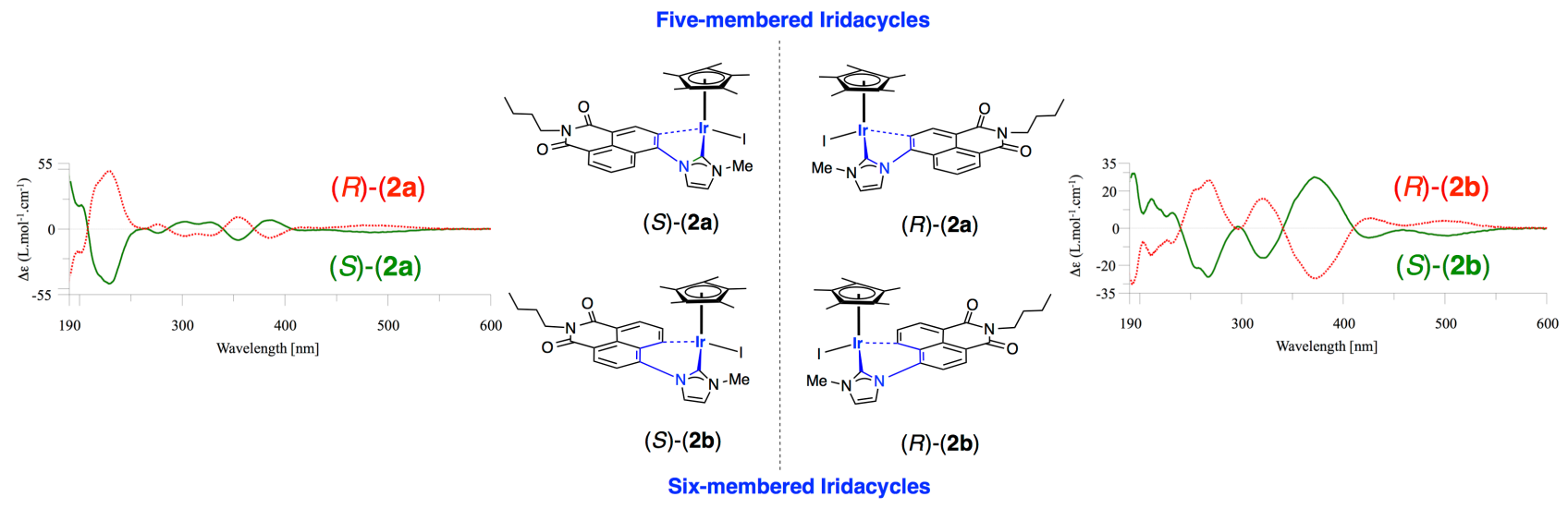

